Article

\title{
Small Scale Hydroelectric Power Plants in Norway. Some Microeconomic and Environmental Considerations
}

\author{
Johannes Idsø ${ }^{+}$ \\ Western Norway University of Applied Sciences, Department of Economics and Business Administration, \\ 6851 Sogndal, Norway; johannes.idso@hvl.no \\ † Current address: Kjørnes, 6856 Sogndal Norway.
}

Received: 24 April 2017; Accepted: 20 June 2017; Published: 27 June 2017

\begin{abstract}
The development of small-scale hydroelectric power plants in Norway is determined by natural conditions, policies, attitudes and property rights. The owner of the river is the central decision maker. It is he/she who decides whether he/she will develop the power plant himself/herself, whether he/he wants to enter into a contract with an external investor and let him/her develop the power plant, whether he/she will sell his/her property rights or postpone the decisions. All available choices will involve risk. In order for him/her to make the best choice, he/she must find the certainty equivalent to each of the choices and choose the one with the highest certainty equivalent. To find the certainty equivalent, we use the utility theory of John von Neumann and Oskar Morgenstern. The owner of the river makes the decision that gives him/her the greatest utility when both economic and non-economic effects are assessed within the opportunity set made by the local and the central authorities.
\end{abstract}

Keywords: small-scale hydroelectric power; Neumann-Morgenstern utility theory; environmental effects of hydro power; hydropower and risk

\section{Introduction}

In Norway, small-scale hydroelectric power plants (SSH) are classified into three categories: "small power plants" have an installed effect between 1 and $10 \mathrm{MW}$; "mini power plants" have an installed effect between $100 \mathrm{~kW}$ and $1 \mathrm{MW}$; and "micro power plants" are power plants with an installed effect of less than $100 \mathrm{~kW}$. In this paper we will, even if the application procedures for micro power plants are easier than for the others, include all three categories into one group and call it SSH.

About 95 percent of the electricity production in Norway is produced by hydro power plants. The public sector has been the dominant provider of electricity and owns almost 90 percent of the hydropower capacity [1]. In the period 1960-1990, Norway had net export in 28 years and net import in three years [2]. In the period 1991-2011, Norway had a net export in 13 years, and a net import in eight years. Total net export in that period was 57 TWh. In January 2017, the average expected annual production from the already developed hydro power system is estimated to be $133.4 \mathrm{TWh}$. Of these, 9.9 TWh (7.4 percent) come from SSH [3].

Norway has endorsed the EU Renewable Directive and has plans to increase its renewable energy ratio from 58.2 percent in 2005 to 67.5 percent by 2020. In order to achieve this target, a common Swedish-Norwegian market for greencertificates has been implemented from 1 January 2012. Renewable power plants where construction had started no earlier than 9 September 2009 and where production will start no later than 31 December 2020 will be entitled to green certificates and can sell one certificate per MWh produced for a period of 15 years. This common green certificate market is expected to increase renewable power production in Sweden and Norway by 28.4 TWh by 2020 [4]. 
Although Norway has the potential to increase the production of electricity from SSH by more than 15 TWh [5] and although Norway uses green certificates to encourage greater production, it is crucial that both investors (IN) and river owners (RO) find this interesting. The behavior of hydro power investors has been discussed in other articles [6,7]. The RO are in a special situation that involves other choices than the IN. There has been an empirical study of the decisions made by the $\mathrm{RO}$. The study in [8] focuses mainly on economic issues. This study is complementary to [8], since we discuss the choices of the $\mathrm{RO}$ in a broader context.

\section{Some Words about the Method}

To get relevant information from ROs, we have used interviews. The best method here is to collect all ROs and then pick some at random for interviews. We have not been in this situation. It is hard to get information since not all ROs want to give interviews. In addition, consultants working in the hydro power business have given us information.

About 20 river owners have sent us signed contracts between ROs and an IN concerning the building and the operation of a hydro power plant. In addition, some ROs have sent us draft contracts prepared by IN. Contracts are normally confidential, so we do not know how representative these contracts are. We have not read all existing contracts.

The Norwegian Water Resources and Energy Directorate (NVE) have to give licenses and handle all applications about hydro power plants in Norway. All papers used in the application process are public and may be downloaded from the web page of NVE [9]. In these papers, there is detailed information about all planned power plants in Norway.

All or nearly all hydro power plants owned by ROs in Norway are limited liability companies. This means that all of the accounts for the last ten years are public and can be downloaded from the website of the Brønnøysund Registers. All information about income and profit as given in Tables 2 and 3 on pages 11 and 16 respectively are downloaded from the Brønnøysund Registers or from companies that collect information from the Brønnøysund Registers. Data used in this paper are bought from the company Bisnode [10].

The information from the Brønnøysund Registers or from companies like Bisnode is not systematized. The user must arrange the information in such a way that it is possible to conduct an analysis. In this case, we used an Excel macro with a loop inside a loop to systematize the accounting information in such a way that we could use SPSS for the final analysis.

\section{The Norwegian Water Resources and Energy Directorate and Its Work}

The Norwegian Water Resources and Energy Directorate (NVE) is a directorate under the Ministry of Petroleum and Energy with responsibility for the management of the nation's water and energy resources. Licenses issued by the NVE are given to specified companies, granting them the right to build and run power installations and accessories as specified in the license. The license also states conditions and rules of operation. NVE has particular emphasis on preserving the environment [9].

In 2004, NVE estimated the potential for development of SSH (in this case, with an effect less than $10 \mathrm{MW}$ ) to 25 TWh [5]. Between 2004 and 2010, NVE gave about 400 new licenses to build SSH. In addition to the license from NVE, one also needs a license from the local authorities to develop $\mathrm{SSH}$. The goal of NVE is the processing of license applications and to ensure that the benefits of the proposed project are greater than the disadvantages [3].

In order to operationalize the task of NVE, we must formulate a profit function of the society. NVE have to process license applications and approve only those applications where $\pi_{s}$ in the following profit function is positive:

$$
\pi_{s}=\pi_{p}-d\left(k_{i}\right)-e(x)+b\left(n_{j}\right)
$$


where:

$$
\begin{aligned}
& \pi_{s}=\text { the economic surplus for the society } \\
& \pi_{p}=\text { the economic surplus (the added value) of the power plant } \\
& d\left(k_{i}\right)=\text { the negative environmental effects measured in money } \\
& e(x)=\text { other negative external effects measured in money } \\
& b\left(n_{j}\right)=\text { positive replacement effects measured in money }
\end{aligned}
$$

In the social profit Function (1), $\pi_{p}$ is the consumer surplus minus the opportunity cost of the produced quantity. We assume an efficient market, and that implies that $\pi_{p}$ is equal to the private profit (the added value) of the SSH.

A SSH may have negative effects on the environment. In Equation (1), the negative environment is a function where $d\left(k_{i}\right)$ where $k_{i}$ is the quantity of the natural resource that is already used in other projects. The derivative $d^{\prime}\left(k_{i}\right)$ is the cost for the society of using one more unit of the natural resource $i$. Both $d^{\prime}\left(k_{i}\right)>0$ and $d^{\prime \prime}\left(k_{i}\right)>0$. That means the cost for the society grows exponentially if more and more of a natural resource is used [11]. Fragmentation of nature may have the same effect. In scientific reports, this is often expressed as the sum effect or the cumulative effect of the projects [12]. If we assume that the project may affect the environment in $n$ different ways, every $i \in n$ have to be considered and translated into a monetary amount.

Hydro power may also be an important part in a sustainable energy power system $[13,14]$. If hydro power production replaces fossil power production, it will be beneficial for the society in $m$ different ways. In Equation (1), the function $b\left(n_{j}\right)$, where $j \in m$, represents these benefits measured in money.

The component $e(x)$ is non-environmental external effects. This may for instance be different negative cultural effects, or negative effects on the interests of the indigenous people, or negative effects on other businesses, such as, for instance, tourism. The so-called "NIMBY" effect (-NIMBY is an acronym for "not in my back yard"-) is a subset of such non-environmental external effects. Sometimes, these external effect are positive, such as when development reduces the risk of floods. This is not usual in cases of SSH, but it may happen.

Since the task of NVE is to ensure a license is given to only those power plants were the benefits are greater than the disadvantages, NVE has to calculate $\pi_{s}$ and approve only those where $\pi_{s}>0$, that is:

$$
\pi_{s}=\pi_{p}-d\left(k_{i}\right)-e(x)+b\left(n_{j}\right)>0 \Rightarrow \pi_{p}+b\left(n_{j}\right)>d\left(k_{i}\right)+e(x)
$$

The sum of the added value $\left(\pi_{p}\right)$ and the benefits of replacing non-sustainable energy production $\left(b\left(n_{j}\right)\right)$ must at least be greater than the environmental damage $\left(d\left(k_{i}\right)\right)$ and other non-environmental external effects $(e(x))$ caused by the project.

The environmental damage $\left(d\left(k_{i}\right)\right)$ is a function of $n$ variables. In practice, that means NVE has to have a list of variables to assess. This list is time dependent and varies as one gets greater knowledge about the nature or the government's attitude towards preservation of the environment. To illustrate, we will give an example from an application sent to NVE in 2016 to develop an SSH with an expected annual production of $3.7 \mathrm{GWh}$. The planned power plant is Auneelva Minikraftverk in the river Sørlivassdraget in Lierne municipality in Norway. The following factors were assessed in this report:

1. Hydrology: NVE require a minimum of water in the river. This requirement is the five-percentile measured in liters per second. There is a requirement for the summer, and one for the winter season.

2. The water temperature, the ice conditions and the local climate.

3. The groundwater and the risk of erosion and flooding.

4. The biodiversity.

5. The fish and freshwater biology.

6. The flora and fauna.

7. The landscape.

8. The cultural effects.

9. The agriculture.

10. The water quality and water supply. 
11. The interests of the indigenous people and reindeer herding.

12. The societal impacts.

13. The consequences of new power lines.

14. The consequences of breaking the dam and pressure pipes.

To measure the negative environmental effects and the external effects and translate these into monetary amounts are not easy tasks, but it is possible to find some help in the literature. See for instance in the textbooks "Measuring Sustainability" [15] and "\{Sustainability Assessment" [16].

\section{The River Owners and Small-Scale Hydro Power Development}

Most farms in mountainous parts of Norway are small. Few farmers own a whole river by themselves. An investigation in the county Sogn og Fjordane in 2012 showed that on average, a river is owned by seven owners. It is possible to find rivers with a single owner and also rivers with more than twenty owners [17], but this is not usual. In our discussion, we use the concept "the river owner (RO)". Usually RO is more than one individual. The starting point of our discussion is that an RO that considers the possibility to increase his/her income by developing a SSH has the following options:

1. Sign a contract with an external investor, and let the investor develop the power plant. In this case, the profit is shared according to the contract. The value of this option is $L_{1}$.

2. RO may finance and develop the power plant by himself/herself. The value of this option is $L_{2}$.

3. RO may sell his/her property right. The value of this option is $S$.

4. Do nothing and wait. In this case, he/she has the possibility to choose one of the other options and choose $L_{1}, L_{2}$ or $S$ in the future. The value of this option is $Z$.

We now follow C.J. Mckenna [18]. We also assume that the RO has a von Neumann-Morgenstern utility function $U(\cdot)$ [19]. This implies that his/her utility function is complete, continuous and transitive. The goal of RO is to maximize his/her utility. From the vector given in Expression (3), he/she chooses what gives the greatest utility:

$$
\text { Maximize }\left[U\left(L_{1}\right), U\left(L_{2}\right), U(Z), U(S)\right]
$$

In (3), all choices are uncertain, but with our assumptions, it is possible to find certainty equivalents. That is the certain amount that generates indifference to a given choice with uncertain outcomes. That means that the choices given in (3) can be translated into certain monetary amounts $m_{j}$. This means for instance that there exist an amount, say $m_{1}$, that makes the RO indifferent between the utility of the uncertain project $L_{1}$ and the amount $m_{1}$. Using standard notation, we may write it in this way: $U\left(L_{1}\right) \backsim m_{1}$.

To be able to choose, $\mathrm{RO}$ has to calculate the certainty equivalents of the utility of all of the choices: $U\left(L_{1}\right) \backsim m_{1}, U\left(L_{2}\right) \backsim m_{2}, U(Z) \backsim m_{z}$ and $U(S) \backsim m_{s}$; and choose the one with the highest certainty equivalent. We will discuss the choices of RO.

Some words about the notation: Below we will describe a lottery with two outcomes $x_{1}$ and $x_{2}$ and related probabilities $p_{1}$ and $p_{2}$ in the following way:

$$
L_{i}=\left[\left\{p_{1}, x_{1}\right\},\left\{p_{2}, x_{2}\right\}\right]
$$

\subsection{Signing a Contract with an Investor}

If $\mathrm{RO}$ chooses the option $L_{1}$ and signs a contract with an investor, his/her new situation may be modeled as a lottery with two outcomes:

$$
L_{1}=\left[\left\{\left(1-p_{1}\right)\left(1-p_{2}\right)\left(1-p_{3}\right)\left(1-p_{4}\right), \pi\left(c_{i}\right)-x\right\},\left\{p_{5}, 0\right\}\right]
$$


where:

$\begin{array}{llll}p_{1} & \in & {[0,1] \text { The probability that there are red-listed species in the river. }} \\ p_{2} & \in & {[0,1] \text { The probability that the municipality rejects the application. }} \\ p_{3} & \in & {[0,1] \text { The probability that NVE rejects the application. }} \\ p_{4}^{i} & \in & {[0,1] \text { The probability the investor reverses his/her decision and stops the project. }} \\ p_{5} & \in & {[0,1] \text { The probability the project is stopped for some reason. }} \\ \pi\left(c_{i}\right) & \geq 0 & \text { The expected risk adjusted net present value of the profit paid to RO. } \\ x & \geq 0 & \text { The net present value of all negative effects measured in money on the RO's utility. }\end{array}$

In (4), the two outcomes are $\left(\pi\left(c_{i}\right)-x\right)$ and zero. If the power plant is built, RO gets a profit of $\left(\pi\left(c_{i}\right)-x\right)$ where $\pi\left(c_{i}\right)$ is the risk-adjusted net present value of the cash flow that he/she receives from the contract with investor $i$ and $x$ is the net present value of all of the negative effects translated into monetary amounts caused by the power plant on the RO's welfare. In practice, $\left(\pi\left(c_{i}\right)-x\right)$ is not always positive. The value of seeing a pristine landscape can be greater than the money from the power plant he/she expects to get out of the project. In this case, RO will not sign a contract with an investor.

\subsubsection{The Probabilities}

We will now discuss what determines the probabilities in Equation (4). Clearly, when the RO chooses, he/she uses his/her subjective probability, but we assume this is the same as the objective or true probability. We assume that $\mathrm{RO}$ is well informed, and we do not discriminate between subjective and objective probabilities. If one of the probabilities $p_{i}$, where $i \in[1,4]$ goes up, the probability that the SSH will be built goes down, and hence, the certainty equivalent $m_{1}$ will go down. The size and changes of the probabilities and of the expected risk-adjusted net present value of the profit to RO will affect the certainty equivalent and the actions taken by RO. This is in line with the results presented on other scientific papers [4].

The first probability $\left(1-p_{1}\right)$ is the probability that there are no red-listed species in the river. In Norway, it is illegal to build a hydro electric power plant if there are red-listed species in the river. We relate this to the profit function of the society, Equation (1) above. If there are red-listed species in the river, the environmental damage $d\left(k_{i}\right)$ is set to $\infty$, hence, $\pi_{s}<0$, and an application will be rejected.

In Norway, there are independent firms that examine the river and write a report, which is submitted with the application to the the local authorities and to NVE. Sending such a report is compulsory. Neither the applications, nor the environmental reports are confidential and may be downloaded from NVE [20]. These studies will differ somewhat from application to application. For example, in most places in South Norway, it is not necessary to examine the consequences for the indigenous people, while this is important in North Norway.

After some discussions about the credibility of these environmental effect reports, NVE decided to do a follow-up study of 20 rivers that had been examined by a company before the application to NVE was sent. The follow-up study was completed in 2012. Some major discrepancies were discovered in the results presented by the companies and the results in the follow-up study. The numbers of red-listed lichens and mosses were 12.8-times higher in the follow-up study: 166 red-listed findings versus 13 discoveries in the small hydro power studies. In the study done by NVE, almost twice as many habitats, including 14 with a very high value, compared with only one in the reports that were submitted along with the applications, were found. Generally, the values were considered to be substantially higher, the scope more negative and the consequences more negative in the follow-up study. Differences in values, scope and consequences varied simultaneously significantly between projects [21].

It is not unlikely that NVE in the future will require that investors or ROs that want to develop an SSH use more resources to examine the river before any license is given. If so $p_{1}$ will increase and reduce the probability of getting an approval on the application. This will also reduce the value of 
the deferral option $(Z)$ or the selling price $(S)$ in Expression (3) and the probability that ROs choose deferral or the sale will be reduced.

The probability $\left(1-p_{2}\right)$ is the probability that the municipality will approve the project. The municipality must obey laws given by the central government. Since many laws are enabling acts, the question whether to approve or not is to some extent a local political question. The local authorities may have several reasons for not approving an application. Generally, many of the reasons may be classified as negative external effects. Here are some examples:

1. The project has for some reason negative effects on other people's welfare.

2. The project has a negative effect on the tourist industry or other businesses.

3. The project has harmful effects on the environment.

4. The project affects the landscape in a negative way. This may happen when it is necessary to mount long transmission cables.

Lawyers have discussed whether it is legal for the local authorities to reject a project because the profit sharing between $\mathrm{RO}$ and IN is disadvantageous for $\mathrm{RO}$ [22]. The attitude of the local authorities will to some extent determine the size of $p_{2}$, and it will be different from municipality to municipality. Municipalities' attitude, involvement and perceived barriers to development of more hydro electric power are discussed by Saha [23].

The probability $\left(1-p_{3}\right)$ is the probability that NVE will approve the project. The task of NVE is to implement the policy of the central government. Policies change by changing concerns about the environment. Media, NGOs and lobbyists try to influence politicians, policy and executive officers. Generally, these organizations may, by their work, change $p_{2}$ and $p_{3}$.

The general economic situation will also play a role. A refusal from NVE has a related annual opportunity cost equal to the annual added value of the power plant if it had been built. A rich country can afford to protect rivers, while a poor country may experience higher opportunity costs and be more likely to give licenses. Both $p_{2}$ and $p_{3}$ decrease with increasing opportunity costs.

From August-December 2016, NVE processed 11 applications concerning SSH. Seven of the applications were rejected [24]. The reasons for the rejections are different from one application to another. For example in one of the applications mentioned above, it was because of negative impacts on the landscape, the reindeer husbandry and the biological diversity. In another application the reason was a very high level of conflict and because of the value of the landscape [24].

The project may also have negative external effects as for instance negative effects on other people's welfare or negative effects on some other businesses. We may relate this to the social profit function in Equation (1). With high value on $e(x)$, the probability that $\pi_{s}<0$ is large. If the negative external effects are large and NVE or the municipality have correct information about this, $p_{2}$ or $p_{3}$ will be close to one, and it is likely that the application will be rejected. A practical problem is to measure the size of negative external effects. This may be difficult both for NVE and the municipality.

The probability $p_{4}$ is the probability that the investor will not develop the power plant even if he/she has signed a contract with RO. After having read more than 20 contracts between an RO and an investor, we see that it is common that the investor for any reason can withdraw from the contract without any economic consequences. On the other hand, we have not found any contract where the $\mathrm{RO}$ has the same option to terminate the contract.

Since in our case there are only two possibilities, develop or not develop the plant, we may simplify Equation (4). If $q$ is the probability that the investor gets a license to build the plant, we will have:

$$
q=q\left(p_{1}, p_{1}, p_{3}, p_{4}\right)=\left(1-p_{1}\right)\left(1-p_{2}\right)\left(1-p_{3}\right)\left(1-p_{4}\right) \Rightarrow p_{5}=1-q
$$

and we get:

$$
L_{1}=\left[\left\{q, \pi\left(c_{i}\right)-x\right\},\{(1-q), 0\}\right]
$$


In our case, the project will stop if there are red-listed species or if the municipality or NVE does not approve or if the investor reverses his/her decision. We see that Equation (4) can easily be extended if there are other institutions involved that have to approve the application.

\subsubsection{The River Owners Profit from a Contract with an Investor}

If $\mathrm{RO}$ has signed a contract with an investor that develops the plant, the investor and the RO will share the profit. Below, we will come back to common contract terms. Here, we discuss this more generally. $\pi\left(c_{i}\right)$ is the risk-adjusted net present value of the cash flow that the RO gets if he/she has signed a contract with investor $i$.

Developing a power plant may have negative effects on the utility of RO. During the construction time, usually between one and three years, RO may be affected by dust, dirt, noise and visual pollution due to a lot of mess on his/her property. During the operation phase, which is literally forever, there are several reasons for the loss of welfare. He/she may for instance miss the beauty of seeing the flow of an untouched river or he/she may suffer because of less fish in the river. If the project has negative effects on other people's welfare, there may be social effects such as the RO may loose friends or have a worse relationship with his/her neighbors. We assume RO is able to evaluate and set a price on all negative effects, and we assume that the negative effects measured in money are $x$. If so, the RO's and the net present value of the risk-adjusted cash flow are less than the disadvantages, we get $\pi\left(c_{i}\right)-x<0$, and $\mathrm{RO}$ will not sign a contract.

A necessary condition for RO to choose $L_{1}$ is that $\pi\left(c_{i}\right)>x$. The negative effect of the power plant on RO's own utility must be less than the risk-adjusted net present value of the generated cash flow. In practice, there may be information problems. It is very difficult to evaluate future negative utility effects. Some ROs have reported they ex ante believed $\pi\left(c_{i}\right)>x$, but ex post, when it was too late, realized that $\pi\left(c_{i}\right)<x$.

\subsubsection{About the Terms of the Contracts}

A usual contract term is that the contract is confidential. This has some methodological implications when writing an article about small-scale hydropower where contracts are discussed.

When doing a research project financed by Sogn og Fjordane County on small-scale hydro power plants, many people sent us some contracts. Most of these contracts were signed, but some were drafts [17]. We received a total of about 20 contracts. In addition, meetings with consultants working in this business and meetings with ROs that were in negotiations with investors gave us information about the terms of some contracts. However, we did not have access to the whole population of contracts in the whole country, and we have never been in position, such that we could pick a random sample of contracts. As a consequence, when we refer to contracts, these are cases. We do not claim that these cases are representative. However, we have a strong suspicion that the investors have read each others' contracts since they seems to be to be made by the same tailor.

In Norway, an RO can choose between several contract partners, normally less than ten. Normally, the contracts have a duration of 30-60 years. Forty- and sixty-year contracts are quite usual. When the time specified in the contract is out, RO has the right to buy the power plant from the investor. The buy back price is different for different contracts. Here are two terms used in many contracts "half of what it would cost to build the power plant at the acquisition date". In another contract, the buy back price was set to "book value". Since a power plant is depreciated linearly with 2.5 percent per year, buying the power plant for book value after 40 years is equivalent to getting it for free if there has been no reinvestments.

When it comes to the sharing of the profit between $\mathrm{RO}$ and the investor, there are two kinds of contracts: gross contracts and net contracts. If the partners have signed a gross contract, $\mathrm{RO}$ will get some percent of the total revenue from the power plant, while a net contract determines how the surplus should be shared between the parties 
A gross contract gives a more predictable payment to RO than a net contract. In the cases that we have seen, the percentage of the revenue that is paid to the $\mathrm{RO}$ varies between three and 10 percent.

If the RO has signed a net contract, the investor and RO share the surplus of the SSH. In many cases, the investor can according to the contract to some extent define what is meant by surplus.

If the RO has signed a contract, he/she has no financial risks. However, in the cases that we have studied, the net present value of the cash flow when signing a contract is usually between 33 and 50 percent of what it would have been if he/she had developed the SSH by himself/herself.

In practice, the investors offer different contracts, so $\pi\left(c_{i}\right) \neq \pi\left(c_{j}\right)$ when $i \neq j$. Few ROs are able to calculate $\pi\left(c_{i}\right)$. To choose the best contract, information is needed; however, there are large information problems, and the information is also asymmetric between the $\mathrm{RO}$ and the investor. When working with the project mentioned in [17], we tried to find an answer to the question: Why do any ROs sign a contact at all? Here are the main reasons:

1. Some ROs are very risk averse. Even if the risks related to the development of SSH are small, there are risks, and some people are very risk averse.

2. Some ROs cannot agree. As said before, a river has normally many owners. Sometimes, they cannot agree. Not all people trust their neighbor.

3. Lack of a leader. Developing a power plant requires a leader. Sometimes, there is no leader among the ROs.

4. RO is not able to finance the project. This may happen when the expected investment cost divided by the expected annual production is high. If this figure is larger than $5 \mathrm{NOK} / \mathrm{kWh}$, it might be difficult to finance the project. However, this question has not been scientifically studied in Norway.

\subsection{RO Chooses to Develop the Power Plant Himself/Herself}

An RO will only choose to build a power plant if he/she finds it profitable. That is, the net present value of the cash flow he/she experiences from the power plant $n$ must be positive. A necessary, but not sufficient condition is:

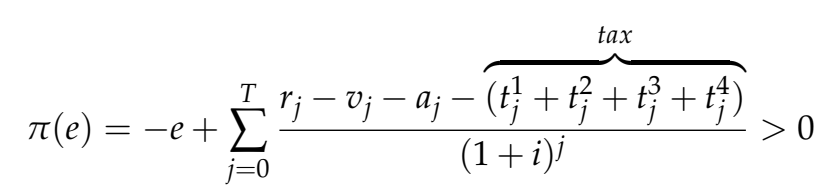

where:

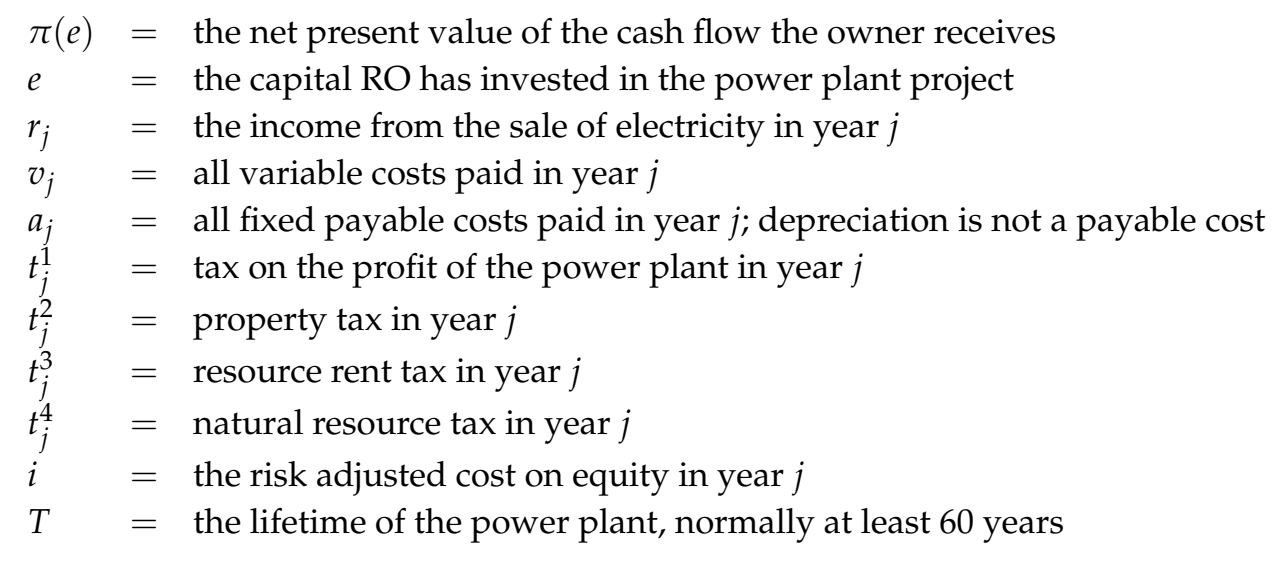

Equation (7) is a necessary, but not sufficient condition for the RO to go ahead with the project. A necessary and sufficient condition is that $n$ must be positive, where:

$$
n=\pi(e)-x>0
$$


where $x$ is the net present value of all negative effects measured in money on RO's utility. This is the same effect as we mentioned in Equation (4). One may ask if $x$ in all cases are so small, are they neglectable? An RO that had planned a possible SSH told me the following story:

"Yesterday my wife walked down to the river. When she came back she was crying. I asked her what was wrong and she said: I mourn because the river will disappear and we will lose this beautiful nature. In that moment the I decided to stop the project".

We do not know how many other projects have been stopped because of similar reasons, but we can conclude that we must take into account the adverse effects of natural destruction and that at least one project has been stopped because of this.

\subsubsection{The Risks of Developing a Small-Scale Hydro Power Plant}

If the RO chooses to develop the power plant himself/herself, he/she will bear all risks associated with the project. The risk is related to the following factors:

1. The expected annual production. The annual production depends on rainfall and the size of the catchment area. The catchment area can be calculated using a map available on NVE's website [25]. By using the Internet application NVE-atlas and the application "Low tide", one can estimate the rainfall field and its hydrological properties. The application "Low tide" uses meteorological data from the period 1961-1990. Based on this, it is possible to estimate the average flow of water that will flow into the planned power plant. Even if the calculated rainfall is based on a 30-year period, there are some uncertainties. According to NVE, the discrepancy between calculated expected rainfall and observed rainfall may be up to 20 percent.

As an example, we will use two cases, both from Sunnfjord in Sogn og Fjordane County in Norway. The two cases are Nydal Kraft and Stølslia Kraft with an expected production of 7.3 GWh and $5.14 \mathrm{GWh}$, respectively. The Table 1 below shows the production measured in $\mathrm{kWh}$ and the production as a percent of expected production in the years 2011-2015:

Table 1. Production measured in kWh and production as a percent of expected production in two small-scale hydroelectric power plants (SSH).

\begin{tabular}{cccccc}
\hline Name & $\mathbf{2 0 1 5}$ & $\mathbf{2 0 1 4}$ & $\mathbf{2 0 1 3}$ & $\mathbf{2 0 1 2}$ & $\mathbf{2 0 1 1}$ \\
\hline Nydal (expected 7,300,000 kWh) & $8,665,758$ & $6,354,643$ & $5,974,126$ & $7,402,959$ & $7,776,902$ \\
Nydal percent of expected & 119 & 87 & 82 & 101 & 107 \\
Stølslia (expected 5,140,000 kWh) & $6,193,010$ & $4,074,295$ & $3,792,117$ & $5,184,148$ & $5,628,571$ \\
Stølslia percent of expected & 120 & 79 & 74 & 101 & 110 \\
\hline
\end{tabular}

From the table, we see that the production varies from 20 percent above to 26 percent below the expected annual production.

Normally, the production in the winter is very small, since most rivers are frozen. About 80 percent of the electricity from an SSH in Norway is produced in May, June and July. The production takes place in the months of snowmelt. To some extent, the production is predictable. If there is plenty of snow in the mountains, we know that the production in the spring will be large.

2. The investment cost will be uncertain, but NVE has made a good tool: a very reliable publication can be downloaded free of charge from the internet [26]. As stated in this publication, the large part of the costs associated with the construction of small power plants is based on standard solutions. In Norway, there are also competent independent consultants that calculate the investment cost. In practice, this means that development costs are largely predictable.

When the expected annual production and investment costs are calculated, one can find the key figure investment cost divided by the expected annual production. This ratio is widely 
used in the power industry as an indicator of the power plant's profitability. The ratio is also used in determining the contract terms for landowners who enters into an agreement with an external investor.

3. The future price of electricity: This, in turn, depends on factors that affect supply and demand such as:

(a) The electricity grid in Norway: In Norway, there are five price areas for electricity. This is due to limited transmission capacity between areas.

(b) Electricity cables to other countries: The transmission capacity between Norway and some other countries will be significantly improved when the planned cables to England and Germany are completed. The Norwegian Government has granted Statnett a license to build two new interconnections for power, one to Germany and one to the United Kingdom. Altogether, this will increase Norway's capacity for power exchange with foreign countries by almost 50 percent. Statnett plans that cable to Germany to be commissioned in 2018, while the cable to the U.K. is scheduled to be completed in 2020 [27].

(c) The demographic trend in both Norway and Norway's electricity trading partners will affect supply and demand and, hence, the price of electricity in Norway.

(d) Changes in the industrial structure in Norway that will affect the demand of electricity.

(e) The growth in energy production in Norway and its electricity trading partners.

(f) For an SSH, the amount of snow in the mountains in the winter greatly determines the annual production.

4. Natural risks such as avalanches and prolonged drought.

5. Technical risks such as technical failures or sand in the turbine.

6. Financial risk: Most small power plants are initially more than 90 percent debt-financed and are vulnerable to interest rate increases [17].

As shown in the above list, many things can go wrong. This is probably also the main reason why practically all landowners who build an SSH establish a limited company.

Despite the risks, many ROs choose to take the risk and develop an SSH without writing a contract with an investor. In 2012, 89 small hydro power concessions were given in Sogn og Fjordane County. In 66 (75 percent) of these cases, the ROs developed the power plant and took all of the risk [17]. This indicates that the loss by signing a contract does not correspond to the risk of not doing so.

Sparebanken Sogn og Fjordane, a local bank, in Sogn og Fjordane County has financed more than $50 \mathrm{SSH}$ and characterized the risk in the small hydro industry as very small. The bank had never had any losses that could be linked to this industry. In 2011, the regular borrowing rate to small-scale hydro plant developments from this bank was 4.5 percent [17]. At that time, this was the same rate as the bank spent on loans for housing to families with regular income. This indicates that the bank regarded loans to $\mathrm{SSH}$ as low risk loans.

We will now look at the choice $L_{2}$. In this case, the RO chooses to finance and develop the power plant himself/herself. He/she will start with the cheapest survey for red-listed species. In this case, we assume, as is in practice today in Norway, that the red-listed species examination is the cheapest. In this case, we may model RO's first step as a lottery $\left(L_{2}\right)$ with two outcomes:

$$
L_{2}=\left[\left\{\left(1-p_{1}^{\prime}\right),\left(L_{2}^{1}-y_{1}\right)\right\},\left\{p_{1}^{\prime},-y_{1}\right\}\right]
$$

where:

$$
\begin{array}{lll}
L_{2}^{1} \quad \geq 0 & \text { is the value of lottery } L_{2}^{1} \\
p_{1}^{\prime} \in[0,1] & \text { is the probability of red-listed species; RO is the applicant } \\
y_{1}>0 & \text { is the cost of the red-listed species investigation }
\end{array}
$$

If there are red-listed species, he/she has to pay the amount $y_{1}$, and the process will not go any further. If the are no red-listed species, the $\mathrm{RO}$ can continue and make plans for his/her power plant. 
To make these plans and write the application to NVE, RO has to engage a company. The cost of the application process is $y_{2}$. The next step is modeled as $L_{2}^{1}$ :

$$
L_{2}^{1}=\left[\left\{\left(1-p_{2}^{\prime}\right)\left(1-p_{3}\right)\left(1-p_{f}\right),\left(\pi(x)-y_{2}\right)\right\},\left\{p_{4},-y_{2}\right\}\right]
$$

where:

$$
\begin{array}{lll}
p_{2}^{\prime} & \in[0,1] & \text { the probability of not being accepted by the municipality; RO is the applicant. } \\
p_{3} & \in[0,1] & \text { the probability of not being accepted from NVE; RO is the applicant. } \\
p_{f} & \in[0,1] & \text { the probability that RO cannot finance the investment. } \\
\pi(c) & \geq 0 & \text { the risk-adjusted expected net present value of the cash flow of the power plant. } \\
y_{2} & >0 & \text { all planning costs. }
\end{array}
$$

If NVE or the municipality do not approve, RO has to pay $y_{2}$, and the process stops.

In Equation (10), we use the probabilities $p_{2}^{\prime}$ instead of $p_{2}$ as in Equation (4). The reason is that it is not obvious that these probabilities are independent of the applicant. The reason is that the municipality may care about the local economy. If the power plant is developed by an external investor, most of the added value of the power plant leaks out of the local economy [28]. For that reason, the local authorities may be more positive toward local owners than toward external investors. Therefore, it may happen that $p_{2}^{\prime}<p_{2}$.

The Table 2 below shows some total results from some SSH from the years 2006-2015. These are all power plants owned by ROs. Power plants owned by external investors are not included. We do not claim that these companies are representative for the whole population of SSH in Norway. However, it is shown as an illustration of the economy in this business.

Table 2. Profit on equity, equity ration and profit after tax in some SSH in Norway.

\begin{tabular}{ccccccccccc}
\hline Year $\rightarrow$ & $\mathbf{2 0 0 6}$ & $\mathbf{2 0 0 7}$ & $\mathbf{2 0 0 8}$ & $\mathbf{2 0 0 9}$ & $\mathbf{2 0 1 0}$ & $\mathbf{2 0 1 1}$ & $\mathbf{2 0 1 2}$ & $\mathbf{2 0 1 3}$ & $\mathbf{2 0 1 4}$ & $\mathbf{2 0 1 5}$ \\
\hline Number of plants & 97 & 100 & 119 & 141 & 148 & 191 & 113 & 178 & 138 & 162 \\
Profit on equity (\%) & 39 & 24 & 33 & 30 & 26 & 37 & 16 & 11 & 10 & 10 \\
Equity ratio (\%) & 15 & 16 & 12 & 13 & 14 & 13 & 19 & 27 & 23 & 30 \\
Profit (millNOK) & 55 & 38 & 52 & 64 & 72 & 107 & 42 & 75 & 42 & 66 \\
\hline
\end{tabular}

From the table, we see that the profit on equity after tax has been high in all years from 2006. The lowest was in 2015 and 2014 when it was 10 percent. This was because of low energy prices in these years.

The profitability of SSH is determined by the investment cost, and these depend on the natural conditions. Some power plants will show very good profitability. The power plant Nydal Kraft mentioned above had a return on equity of 28.7 percent over the years 2006-2015. Other power plants have trouble gaining profitability. Very much depends on the initial investment and the annual production.

\subsection{RO Chooses to Defer the Development the Power Plant or Sells His/Her Rights}

Building a hydro electric power plant is not a now or never project. The RO may start the development of the plant today or he/she may defer it to the next year. This flexibility has a value [29], but the value is time dependent. An example: If we assume the value of the landscape $(v)$ is a function of what is it is already used for $(b)$, we have $v=f(b)$, where $f^{\prime}>0$ and possibly also $f^{\prime \prime}>0$. If the development continues with more and more projects that occupy nature, the value of the landscape and, hence, its opportunity cost may be higher in the future. If NVE in the future has the same instructions as today, the probability for an applicant to get a denial will be higher in the future. 
This will, ceteris paribus, reduce the value of the deferral option $(Z)$ and its certainty equivalent in Equation (3).

In some cases, ROs do not want to develop the power plants now. There may be many reasons for that: he/she may expect the investment costs to go down in the future or may expect that investors will offer better conditions in the future. In any case, by choosing not to develop the power plant now, he/she is holding an option that has a certain value. The value of this option and its certainty equivalent depend on the RO's information and expectations about the future. This is discussed in [4].

Sales are always a possibility, but it just means that the new owner enters into the same situation as the former where the relevant choices are $L_{1}, L_{2}$ or $Z$.

\section{Two Cases}

RO has the possibility to sign a contract with IN. IN has special knowledge of how to build and operate a power plant.

There are several INs in this industry. The leading company is Småkraft AS. According to their web page, this company has signed contracts with 850 people that owns a river or a part of a river. Småkraft has 270 SSH in 89 municipalities in Norway. The construction of all of these SSH is not finished yet. However, when it is finished, the production capacity of its portfolio is $2700 \mathrm{GWh}$ [30]. Småkraft is one of the pioneers in the SSH industry in Norway. Småkraft is owned by the German company Aquila Capital.

There has been very little research on the contracts between IN and RO in Norway. Questions included: Who takes the initiative for the cooperation? How are the negotiations going? Who develops the contracts? How many IN are considered by the RO before writing a contract? How many ROs have signed a contract with IN, and how many ROs have chosen to build themselves? What is the financial benefit of those who have signed contracts compared to those who chose to build themselves? How similar contracts are from different INs? Is the SSH industry organized in such a way that we get an efficient resource utilization? These are questions that no one has researched.

If one wishes to research the SSH industry, then one will quickly encounter problems. The reason is that many contracts, maybe all, are confidential. This means that the researcher will have trouble gaining insight into the terms of the contract. In this section, we will take a closer look at a contract. In this case, we got permission to publish the terms if no names were mentioned. In our case, the contract was signed in 2004. The contract regulates the condition between the RO and investor (IN) about an SSH in western Norway. According to another RO, this contract is identical to five other contracts between the ROs and the same IN in the same geographical area. However, since we have not read all existing contracts, we cannot say that this contract applies in general.

The contract was about a waterfall where the estimated annual output was 28 GWh. The application was processed by NVE in 2009. The NVE rejected the application because the power plant would destroy the beautiful nature, as well as the habitat of red-listed species. All in all, a full development would have major negative consequences. For this reason, NVE authorized a minor development, so that expected output was $7 \mathrm{GWh}$, down from $28 \mathrm{GWh}$. The duration of the contact is 40 years; that means it is valid until 2044. We will now discuss the most central points of this contact.

\section{Case 1: RO Signed a Contract}

In the following, we will go through the terms of a contract in the same order as in the contract. We comment on some of the terms.

What the contract it is about: The first point in the contract tells what the contract is about. In this case, it says: This agreement is an agreement between RO and IN and gives IN the right to build and operate the power plant that utilizes the waterfall in River XX. This river has a height difference of about $400 \mathrm{~m}$.

Comment: The property right of the SSH belongs to IN. This is not explicitly said in the contract, but it is said implicitly in the agreement by giving IN the right to sell its rights. This means that IN can 
sell the power plant together with the contract. There have been many sales of SSH in recent years. In 2015, the Norwegian company Statkraft AS sold Småkraft AS Small to Aquila Capital. The possibility for IN to sell is important for the $\mathrm{RO}$, since he/she, as a consequence, does not know who will be on the other side of the table in the future. It is therefore important that absolutely all conditions are written in the contract. Oral agreements have a tendency to be forgotten when new owners take over.

The construction phase: IN has the right to do what suits him/her for the construction process to take place in the most efficient way. It concerns the location of the power plant, digging, temporary placement of stone and soil, construction of new roads and the use of existing roads.

Comment: The agreement says nothing about what the IN will do in retrospect to clean up. In practice, there have been cases where $\mathrm{RO}$ has lost or impaired the quality of the drinking water of $\mathrm{RO}$ as a result of the construction. What will happen in such cases is not governed by the agreement.

It is IN that determines where the power station is to be located. In some cases, the power station has been located so close to the living house of the RO that the RO can hear the generator. In the long run, some may find such sounds troublesome.

An option to build: The contract states that IN has an option to build the power plant. This option lasts for five years and will be extended if there is no permit from the authorities due to late processing.

Comment: According to the contract, IN has no obligation to build the power plant. If the market changes or IN for some reason finds it appropriate, he/she may in principle set a line over the entire agreement. Before the building has started, IN can at any time and for any reason terminate the contract. If IN decides not to build the power plant, $\mathrm{RO}$ cannot claim any compensation. $\mathrm{RO}$ is not given the same opportunity to terminate the contract if he/she regrets.

Sometimes, it takes many years from the contract being signed until the production starts. These may be cases where the application process takes a very long time or when the SSH is dependent on new transmission cables. In Sogndal municipality in western Norway, the RO signed a contact regarding five SSH in 2004. The production is expected to start in 2019, fifteen years after the contract was signed.

Rent of land: IN has to pay a small rent for the land where the power station is located. In this case, the rent is 1000 NOK (about 106 euros) per year.

Water-irrigation: IN must provide water to the existing irrigation system.

Comment: The watering requirement will vary from year to year and may also change during the 40 years for which the contract applies. The contract does not take into account that watering needs can increase.

Income: IN is responsible for the sale of all production and green certificates. $\mathrm{RO}$ is given the right to buy $1 \mathrm{GWh}$ per year at a price equal to the price in the spot market.

Comment: The option to buy $1 \mathrm{GWh}$ is beneficial to RO. An example: Suppose RO draws a fixed price agreement with a power company for the purchase of electricity for 50 øre (one øre is one cent of $\mathrm{NOK}$ ) per $\mathrm{kWh}$. If the spot price is below 50 øre, they can buy power from the power plant, but if the spot price is more than 50 øre, they should buy power at the fixed price. The ability to buy electricity at the spot price gives the $\mathrm{RO}$ greater flexibility, and greater flexibility always has a certain economic value. In order to be able to use the purchase option, it is assumed that the RO has the opportunity to swap the power supplier at short notice.

The sharing of the profit: The contract states that the profit is shared equally with 50 percent to each of the parties. It is also possible for RO to choose between pure profit sharing or profit sharing combined with a annual minimum amount of money in the first 10 years.

Comment: If profit sharing combined with a annual minimum amount of money is chosen, some of the money will be regarded as a loan from IN to RO that has to be paid back later. Compared with pure profit, profit combined with an annual minimum only gives RO cash flow with another profile. The net present values of these cash flows are about the same. For that reason, we will only discuss the option of pure profit sharing. 
Since the SSH has no reservoir, the production is only dependent on rain and melting of snow and ice. It is also illegal to manipulate the production by allowing water to flow outside the turbine if the turbine can swallow more water. Once the power plant is built, the production (but not the income) is independent of the actions of IN and RO.

We define the private profit of the power plant in year $i$ as:

$$
\pi_{i}^{p}=r_{i}-k_{i}-t_{i}
$$

where:

$$
\begin{aligned}
& \pi_{i}^{p}=\text { the private profit of the power plant in year } i . \\
& r_{i}=\text { the total revenue from the sale of electricity and green certificates in year } i \\
& k_{i}=\text { the market price of the resources that is used in the production in year } i \\
& t_{i}=\text { the tax to the state and the municipality in year } i .
\end{aligned}
$$

The private profit $\pi_{i}^{p}$ is the amount of money that is available for sharing between IN and RO. According to the contract, it is not $\pi_{i}^{p}$ that is used when profit is shared. This is a conflict of interests between IN and RO, since a higher profit share to RO means a lower profit share to IN and vice versa. Even if the contract states a fifty-fifty sharing of the profit, a contact between RO and IN does only indirectly determine how the private profit is shared. The reason is that the contract defines what is meant by costs and revenues. In that way, a new contract surplus $\left(\pi_{i}^{c}\right)$ that is different from the private profit $\left(\pi_{i}^{p}\right)$ is defined. It is this defined contract surplus $\left(\pi_{i}^{c}\right)$ that is used when the profit is shared. In our case, we will see that the contract surplus is less than the private surplus $\left(\pi_{i}^{c}<\pi_{i}^{p} \forall \pi_{i}^{p}>0\right)$. That means IN will get more than $0.5 \times \pi_{i}^{p}$ even if the contract specifies a fifty-fifty sharing.

We will now explain why the "real surplus" $\left(\pi_{i}^{p}\right)$ normally is different from the contract surplus $\left(\pi_{i}^{c}\right)$. According to the contract, income is all production sold at market prices where the market price is defined as the spot price on Nord Pool's power market, settled hour by hour.

In practice, this is common with hedging contracts: when there is very much snow in the mountains, people working in the electricity branch know that the electricity price will be low in the spring; when the SSH has most of its production. This is due to high production combined with bottlenecks in the transmission system. In years with plenty of snow, many owners of SSH sign a fixed price contract. In this way, the actual income from the sale of electricity may differ quite greatly from the income calculated by using the Nord Pool spot price as stated by the contract. However, without special information, nobody can in the long run expect to beat the market.

In terms of costs, this is defined as all running costs for the operation and maintenance of the power plant, as well as costs that are associated with power sales. These costs are not precisely defined, and thus, it is not clear how such costs are to be calculated.

An example: If IN that runs the production wants to do an improvement, it is not specified how to calculate the costs: How many men and hours have been used, and what are their salaries? IN is the expert in running power plants, and RO does not know how to do this. IN has the opportunity to exploit his/her private information to increase his/her share of the profit. This is a special case of the principal agent problem.

Another important and large cost is the cost of capital. The cost of capital that is used when calculating the contract surplus $\left(\pi_{i}^{c}\right)$ is not linked to loans raised to finance the investment. The contract states that the basis for the capital cost is the book value of the plant before deduction of depreciation for the year. The interest rate is stated as a real return requirement of 4.4 percent. Furthermore, it is also explained how the nominal interest rate $(p)$ is calculated. The contract gives the following formula:

$$
p=\frac{(1+r)(1+j)-1}{(1-s)}
$$


where $p$ is the normal interest rate before tax, $r$ is the real return requirement (4.4 percent), $j$ is annual inflation and $s$ is the tax rate. If the annual inflation is two percent and the tax rate is 28 percent, we find that the nominal cost of capital before tax is nine percent.

Is a nominal cost of capital of nine percent unreasonably high? The answer depends on the risk of the project. Sparebanken Sogn og Fjordane, a regional bank in western Norway, has financed more than fifty SSH and never had any loss on SSH. This bank claimed it used a nominal interest rate of 4.5 percent on all loans to SSH. If the booked value of the power plant is 50 million NOK and the cost of capital is reduced from 9 down to 4.5 percent, the contract surplus $\left(\pi_{c}\right)$ will increase with 2.25 million NOK, and the profit of RO increases with 1.125 million NOK.

The contract term that gives IN a real interest of 4.4 percent after tax on all capital tied up in the project may give IN a high return on equity even if the basis for profit sharing $\left(\pi_{c}\right)$ is zero. This is the case when the internal rate of return of the SSH is higher than the borrowing rate and the equity ratio is small; in cases of high gearing. In such cases, the private profit $\pi_{i}^{p}>0$, but $\pi_{i}^{c}=0$. In this case, IN gets the whole difference between $\pi_{i}^{p}$ and $\pi_{i}^{c}$.

The right to buy the SSH: After 40 years, RO has the right to buy the SSH. In this contract, the price is set to the "technical value", where the technical value is defined as the new acquisition value of a corresponding plant.

Comment: With a linear depreciation of 2.5 percent, which is usual in the power branch, the book value of the SSH is zero (if no reinvestments have taken place). After 40 years, IN has, through the depreciation and the contract term about the cost of capital, gotten back all of the capital he/she invested in the project. He/she has also had a good return on his/her equity.

ROs who buy back the SSH will thus end up paying for the power plant 1.5-times: one time after 40 years, when he/she buys it, and a half time through the annual deduction of depreciation before fifty-fifty profit sharing.

We have seen some contracts where the buy back price is set to the book value after 40 years. In these cases, the price is 1 NOK if there have been no reinvestments in these 40 years.

Forty years may seem to be a long time, and in many industries, production facilities have little or no value after 40 years. This is not the case in the hydro power industry. In Norway, there are many power plants that are much older than 40 years, and they are still producing electricity. For instance, Årøya Kraftverk in Sogndal municipality is 76 years old and is still producing electricity. Another example is Hammeren Kraftstasjon outside Oslo. This power plant was built in the year 1900. Still, it produces $16 \mathrm{GWh}$ per year.

\section{The Profit Sharing}

We will now calculate the profit that RO gets if he/she has signed a contract with IN and if he/she develops the SSH by himself/herself. We use the contract mentioned in the section above, and the cost and income figures are based on historic figures from an SSH. That means we used the real figures for the first seven years and assume the figures in the future 33 years will be identical to the figures in the first years.

The calculations are based on the following assumptions:

1. Average annual income from sale: one million NOK.

2. Grid costs per year: 30,000 NOK.

3. Running costs per year: 40,000 NOK.

4. Property tax per year: 0.5 percent of book value.

5. Tax rate: 28 percent.

6. Banks borrowing rate: five percent.

7. Total investment: six million NOK where 600,000 is equity and the rest is loan.

8. Linear annual depreciation of 2.5 percent over 40 years.

9. Real (inflation adjusted) cost of capital after tax is three percent. 
Based on these assumptions and the terms in the contract, RO gets a net present value of 3.2 million NOK if he/she signs a contract and 9.8 million NOK if he/she built the SSH himself/herself. We found that $\mathrm{RO}$ will get 32 percent of the net present value, while IN will get 68 percent. As mentioned above: since contracts normally are confidential, it is not possible, due to lack of information, to say if the sharing percentage of 32 to the $\mathrm{RO}$ is good or not good for the RO compared with other contracts.

\section{Case 2: The RO Builds the Power Plant Himself/Herself}

This case is Seimsdal Kraft in Årdal municipality in western Norway. The information is based on a lecture given by $\mathrm{RO}$, the interview done by students [31] and the accounting information from the Brønnøysund Registers.

In 2004, landowners in Seimsdalen were visited by hydro power investors, such as Småkraft, Fjellkraft and Grønnkraft. According to the landowners, the investors promised "gold and green forests" to the landowners if they would sell or rent out their property rights of the waterfall. Since the investors were so interested, RO thought that it must be more profitable to build the power plant themselves. Therefore, all landowners founded a company. They also invited the local hydro power company Årdal Energi KF to join. The reason for inviting Årdal Energi KF to be one of the owners was their competence. Årdal Energi KF knew how to build and operate a hydro power plant.

Together, there are now 15 owners where Årdal Energi KF is the largest (33.99 percent). The 15 owners invested altogether three million NOK in the project. In addition, they obtained a loan of 45 million NOK. The total investment was about 48 million NOK.

The application process took four years. According to ROs, this was due to resistance from people who believed that the power plant would impair nature. The construction and application process took a total of five years, and in 2011, the production started. According to ROs, they are now (spring 2017) pleased that they did not sign a contract with INs. We have calculated some economic results based on the accounting figures since the start of the production in 2011. See Table 3.

Table 3. Profit on equity, equity ration and profit after tax in some SSH in Norway.

\begin{tabular}{lccccc}
\hline Year & $\mathbf{2 0 1 5}$ & $\mathbf{2 0 1 4}$ & $\mathbf{2 0 1 3}$ & $\mathbf{2 0 1 2}$ & $\mathbf{2 0 1 1}$ \\
\hline Income (1000 NOK) & 9796 & 7059 & 7583 & 5951 & 5267 \\
Return on total capital (percent) & 12.7 & 9.4 & 10.4 & 6.7 & 7.0 \\
Return on equity (percent) & 41.5 & 31.4 & 44.8 & 30.4 & 65.7 \\
Annual result after tax (1000 NOK) & 2746 & 1667 & 1750 & 799 & 1104 \\
Debt (1000 NOK) & 37,571 & 38,376 & 40,565 & 40,886 & 46,779 \\
Equity (1000 NOK) & 7395 & 5850 & 4783 & 3032 & 2233 \\
\hline
\end{tabular}

ROs report that a substantial part of the income is from the sale of green certificates. We notice that the return on equity was more than 30 percent in the weakest year (2012). The accounting figures for 2016 are not ready yet, but according to ROs, the debt in spring 2017 is 3.5 million less than in 2015 . That means 2016 will be as good as the years before.

\section{Contract or Not a Contract}

There has been no research on the annual numbers of contracts that are signed between ROs and INs. There are however indications that contracts are more popular among ROs now (in 2017) than before. Regulations, uncertainty and low electricity prices have made it more risky for land owners to develop hydropower themselves, and larger companies have in later years been responsible for the further development [32].

The main reason some ROs have given us is that in times of low electricity prices, the risk of SSH is large. In order to obtain the necessary capital, ROs often have to pledge other assets than the power plant. If the RO signs a fifty-fifty contract, he/she gets in year $i \max \left[0.5 \pi_{i}^{c}, 0\right]$. If he/she himself/herself builds the power station, he/she may, even if we have not observed any such cases, 
loose the entire property. On the other hand, as shown in Table 3 on page 16, an SSH may be very profitable for the $\mathrm{RO}$ if he/she does not sign a contract.

\section{Conclusions}

The development of small-scale hydroelectric power plants in Norway is determined by natural conditions, policies, attitudes and property relations. Natural conditions, NVE, municipalities, financial institutions and river owners will together determine how many new power plants are built.

$\mathrm{RO}$ is the central decision maker when it comes to the development of small-scale hydroelectric power plants. It is he/she who decides whether he/she will try to build the power plant himself/herself, whether he/she will leave this to an external investor or whether he/she will sell the fall rights or postpone the decisions. In practice, we see that it is often investors who take the initiative and try to persuade the RO to enter into a contract. Many contracts have been signed as a consequence of this, but we also see many examples for which the RO has financed and built the power plant himself/herself.

To capture all aspects of RO's investment decisions and to make the right decision, he/she has to assess the utility of each possible outcome. To do that, we propose the following procedure:

1. Before any practical and often costly decisions are made, $\mathrm{RO}$ must evaluate his/her utility of seeing the river flow as it has always done. Development of a power plant may also destroy fishery resources and have some external effects that reduce other people's welfare. Such effects must also be considered. If he/she comes to the conclusion that the utility of an unchanged situation is greater than anything else, he/she should not do anything with the river.

2. If RO believes that his/her utility will increase if a cash flow-generating power plant is built, he/she must take the next step: to get information about the building costs of the power station and the size of normal production. Here are two possibilities:

(a) Tell an investor he/she might be interested in signing a contract and ask him/her to calculate the expected investment cost and the expected annual production. This costs nothing for RO.

(b) Ask an independent consultant to calculate the expected investment cost and the expected annual production. $\mathrm{RO}$ has to pay for the consultant.

One would think that either one chooses $a$ or $b$; the answer would be about the same. However, this does not always occur this way. An example from Balestrand municipality in 2016 is as follows: The questions above were given both to an independent consultant and to an investor that wanted to sign a contract with RO. Both agreed that the expected annual production of the planned power plant was $4.5 \mathrm{GWh}$, but while the independent consultant calculated the investment cost to be 12.7 million NOK, the investor calculated it to be 22.9 million NOK.

One possible reason for this difference is that IN wants a contract, and the probability that the RO will sign a contract is larger when the investment cost and then the risk of the project are high. In order to signal high risk, IN chooses expensive solutions when calculating investment costs. This is a hypothesis that one could investigate further.

3. Once $\mathrm{RO}$ has received information about the size of the investment and the expected annual production, he/she may, based on the expected electricity prices, calculate the profitability of the project. If the expected net present value of the project is positive, he/she has two choices:

(a) Sign a contract with an investor.

(b) Finance and build the power plant himself/herself.

All available choices will involve risk. In order for him/her to make the best choice, he/she must find the certainty equivalent to each of the two choices above and choose the one with the highest certainty equivalent.

4. When the RO has found the alternative with the highest certainty equivalent, he/she has to evaluate his/her utility of this alternative together with all non-economic effects. 
RO must make the decision that gives him/her the greatest utility when both economic and non-economic effects are assessed within the opportunity set made by the local and the central authorities.

Conflicts of Interest: The authors declare no conflict of interest.

\author{
Abbreviations \\ SSH Small-scale hydroelectric power plant \\ RO The owner/owners of the river \\ NVE The Norwegian Water Resources and Energy Directorate \\ IN Investor who specializes in building and operating small hydro electric power plants
}

\title{
References
}

1. Førsund, F.R. Hydropower Economics; Springer: New York, NY, USA, 2007.

2. Magne, H.; Ann Christin, B. (Eds.) Fakta om Energi: Utviklingen i Energibruk i Norge; Technical Report; Statistics Norway: Oslo, Norway, 2011.

3. NVE. Available online: https://www.nve.no/energiforsyning-og-konsesjon/vannkraft/vannkraftpotensialet/ (accessed on 27 February 2017).

4. Linnerud, K.; Simonsen, M. Swedish-norwegian tradable green certificates: Scheme design flaws and perceived investment barriers. Energy Policy 2017, 106, 560-578

5. Jensen, T. (Ed.) Beregning av Potensial for Småkraftverk i Norge; Technical Report 19; NVE: Oslo, Norway, 2004.

6. Fleten, S.-E.; Linnerud, K.; Molnár, P.; Nygaard, M.T. Green electricity investment timing in practice: Real options or net present value? Energy 2016, 16, 498-506.

7. Fleten, S.-E.; Maribu, K.M.; Wangensteen, I. Optimal investment strategies in decentralized renewable power generation under uncertainty. Energy 2007, 32, 803-815.

8. Linnerud, K.; Andersson, A.M.; Fleten, S.E. Investment timing under uncertain renewable energy policy: An empirical study of small hydropower projects. Energy 2014, 78, 154-164.

9. NVE. Available online: https://www.nve.no/licensing/(accessed on 27 February 2017).

10. Bisnode. Available online: https:/ / www.soliditet.no (accessed on 6 July 2017).

11. Bateman, I.; Turner, R.K.; Pearce, D.W. Environmental Economics: An Elementary Introduction; Harvester Wheatsheaf: London, UK; New York, NY, USA, 1993.

12. Jordhøy, P.; Strand, O. Villreinen i Fjellheimen; Technical Report 411; Norsk Institutt for Naturforskning: Trondheim, Norway, 2009.

13. Varun; Prakash, R.; Bhat, I.K. Energy, economics and environmental impacts of renewable energy systems. Renew. Sustain. Energy Rev. 2009, 13, 2716-2721.

14. Margeta, J.; Glasnovic, Z. Sustainable electric power system: Is it possible? J. Energy Eng. 2010, 136, doi:10.1061/(ASCE)EY.1943-7897.0000027.

15. Bell, S.; Morse, S. Measuring Sustainability: Learning From Doing; Earthscan: London, UK, 2003.

16. Gibson, B.; Hassan, S. Sustainability Assessment: Criteria and Processes; Earthscan: London, UK, 2005.

17. Johannes, I. Småkraft og RegionaløKonomisk Vekst; Sogn og Fjordane University College: Sogndal, Norway, 2012.

18. Mckenna, C.J. The Economics of Uncertainty; Wheatsheaf Books: Sussex, UK, 1986; pp. 21-28.

19. Von Neumann, J.; Morgenstern, O. Theory of Games and Economic Behavior; Princeton University Press: Princeton, NJ, USA, 1953.

20. Norwegian Water Resources and Energy Directorate (NVE). Available online: https://www.nve.no/ konsesjonssaker/ (accessed on 23 June 2017).

21. Gaarder, G.; Høitomt, T. Etterundersøkelser av Flora og Naturtyper i Elver Med Planlagt; Technical Report 102; NVE: Oslo, Norway, 2015.

22. Digernes, D. Vilkår for Konsesjon til Erverv av Fallrettar Etter Jordlova; Sogn og Fjordane University College: Sogndal, Norway, 2012.

23. Saha, P.; Idsø, J. New hydro power development in norway: Municipalities' attitude, involvement and perceived barriers. Renew. Sustain. Energy Rev. 2016, 61, 235-244.

24. Sigurd Aarvig. Available online: http:/ / energiteknikk.net/2016/10/over-60-prosent-avslag-pa-smakraftsoknader (accessed on 6 March 2017). 
25. Norwegian Water Resources and Energy Directorate (NVE). Available online: https://gis3.nve.no/link/ ?link=nedborfelt (accessed on 23 June 2017).

26. Ed. Kjell Erik Stensby. Kostnadsgrunnlag for Små Vannkraftanlegg; Technical Report 1; NVE: Oslo, Norway, 2010.

27. Sættem, J.B. Nye Kabler til Utlandet Gir Dyrere Strøm. Available online: https:/ /www.nrk.no/norge/_utenlandskabler-gir-dyrere-strom-1.11982866 (accessed on 23 June 2017).

28. Armstrong, H.; Taylor, J. Regional Economics and Policy; Blackwell Publishing: Oxford, UK, 2007.

29. Antikarov, V.; Copeland, T.E. Real Options: A Practitioner's Guide; Texere: New York, NY, USA, 2003.

30. Småkraft. Available online: http://www.smaakraft.no/topp/om-oss/ (accessed on 23 June 2017).

31. Beheim, S.F.; Nes, M.S.; Rath, L.M. Can Investing Locally in Renewable Energy Pay Off? Student Work; Western Norway University of Applied Sciences: Sogndal, Norway, 2017.

32. Garbarini, G.; Nguyen, T.-T.; Karlsen, E.H.; Yttri, G. Small-Scale Hydroelectric Power a Promising Enterprise in Demanding Contexts. Postdoctoral Thesis, NorRen Summer School, Sogndal, Norway, 2016.

(c) 2017 by the author. Licensee MDPI, Basel, Switzerland. This article is an open access article distributed under the terms and conditions of the Creative Commons Attribution (CC BY) license (http://creativecommons.org/licenses/by/4.0/). 